\title{
Estudio de la Evolución Tecnológica en Empresas de Celulares a Partir de la Actividad de Patentamiento.
}

\author{
Carlos Hernández', Domingo González²
}

\begin{abstract}
En el contexto actual a nivel mundial, las comunicaciones inalámbricas se han convertido en imprescindibles. Por ello, el objetivo de este trabajo es proporcionar una comprensión de la evolución tecnológica de la industria de celulares, a partir de tres estudios de caso de las empresas Nokia, Huawei y ZTE. Inicialmente, se expone cómo se ha venido desarrollando la tecnología de las comunicaciones inalámbricas. Asimismo, se destaca a la actividad de patentamiento como un indicador tangible de la actividad I+D, en particular de las empresas en estudio. La segunda parte del trabajo trata los estudios de caso basados en el estudio de la actividad de patentamiento de los últimos años. Finalmente, se presentan las semejanzas y diferencias entre los casos estudiados y las conclusiones sobre la actividad de patentamiento en la industria.
\end{abstract}

Keywords: comunicaciones inalámbricas; tecnología de celulares; patentes; i+d.

Departamento de Ingeniería, Pontificia Universidad Católica del Perú.Av. Universitaria I80 I, San Miguel, Lima 32, Perú. Phone: +5 I I6262000. e-mail: 'carlos.hernandez@pucp.edu.pe, ${ }^{2}$ dgonzal@pucp.edu.pe 


\section{Introducción}

A nivel mundial, según la Unión Internacional de Telecomunicaciones (UIT), se tiene más de cinco mil millones de subscripciones de líneas de celulares, superando así en los últimos años a las subscripciones de líneas fijas (UIT, 20I I). Eso significa que cada año se tienen que vender un número elevado de equipos celulares tanto para las líneas nuevas como para los usuarios que renuevan el equipo celular. Según los informes Worldwide Mobile Phone Tracker de International Data Corporation (IDC) en el 2010 se vendieron, a nivel mundial, I 388.6 millones de equipos celulares y cerca al $70 \%$ de estos fueron fabricados por cinco compañías, es decir, estas concentran el mayor volumen de fabricación (DOTMOBI, 20II).

El mercado de equipos celulares es muy activo, lo cual indica que las compañías están innovando en esta industria e ingresando cada vez a más países.Además, actualmente existen más compañías fabricantes, por ejemplo en Alibaba.com, el $201 \mathrm{I}$, están registradas más de 700 fabricantes de celulares y casi 1600 mayoristas a nivel mundial, el mayor número de estos son de China, Hong Kong y Estados Unidos (ALIBABA GROUP, 20llb). Según IDC, Nokia se mantiene durante varias años como el primer fabricante a nivel mundial, tras haber llegado en el 2008 a tener una participación de mercado de casi un 40\%; no obstante el $201 \mathrm{I}$ tiene menos del $30 \%$ (IDC, 2007; IDC, 2008; IDC, 20I0; IDC, 20I I) y ZTE y Huawei están lanzando al mercado celulares con precios bajos entre otros fabricantes (ALIBABA GROUP, 20I la).

Las empresas de celulares deben usar la innovación como principal herramienta para participar del mercado, pues si no innovan perderán el mercado con el tiempo. Además es importante el uso del patentamiento como herramienta para proteger su tecnología e invenciones, de esta manera podrán salvaguardar la inversión que hicieron en ellas.

Este trabajo presenta una investigación exploratoria y cuantitativa sobre la evolución tecnológica de las empresas de celulares a partir de la actividad de patentamiento de tres estudios de caso, exponiendo la evolución de la industria de la telefonía celular, la actividad de patentamiento, la metodología, los casos de las empresas consideradas en el estudio y las conclusiones correspondientes.

El objetivo del presente trabajo es explorar la evolución tecnológica de la industria del celular a partir del patentamiento como un indicador de I+D y brindar evidencias sobre la actividad de I+D que tienen Nokia, Huawei y ZTE en los últimos años (cantidad de patentes). Del mismo modo, se describen cuáles son las tecnologías que utiliza la telefonía celular y que han evolucionado en los últimos años, ubicando esta evolución en el contexto de los resultados económicos y la participación del mercado de estas compañías.
El presente trabajo se ha organizado en tres secciones. En la primera sección se explica la evolución y el escenario actual tecnológico de la telefonía celular y se presenta una introducción de la actividad de patentamiento. En la segunda sección se describen la metodología empleada en la investigación. En la tercera sección se presentan los estudios de caso y los resultados encontrados. La última sección incluye las conclusiones correspondientes.

\section{La evolución de la telefonía celular}

En la industria de la telefonía celular están las empresas fabricantes de equipos para las redes de celulares, las cuales producen por un lado equipos celulares y por otro, celdas de celulares. Sin embargo cabe mencionar que estas redes también requieren otros equipos como las centrales telefónicas y dispositivos de redes para las interconexiones (Keith, 2004b). A continuación se describe cómo se desarrolló la tecnología en esta industria de celulares en base a la información provista por Keith (2004a) y Farley (2005) y cómo el mercado correspondiente está distribuido en la actualidad.

\section{De la radiotelefonía a la telefonía celular}

Desde el desarrollo del teléfono, a mediados de la década de 1870 , y la radio, a fines del siglo XIX, se buscaron diferentes formas de fusionarlos $y$ ofrecer la movilidad de la radio con la capacidad del teléfono. En 1919 se disponía de radioteléfonos buque-tierra, $y$ en la siguiente década se desarrollan los radios de dos vías para los vehículos de la policía y las ambulancias. La segunda guerra mundial produjo una serie de mejoras en la radio como la facilidad de uso y proporcionar conversaciones fiables. En 1945 American Telephone \& Telegraph (AT\&T) anunciaba que podía fabricar el radioteléfono para los automovilistas de EEUU y el 17 de junio de 1946, AT\&T ofrecía el Servicio de Telefonía Móvil (Mobile Telephone System - MTS) por medio de su filial South Western Bell en St. Louis, que posteriormente se extendió a otras ciudades. Esta tecnología requería de un equipo pesado y tenía un alto costo por el servicio. El sistema MTS tenía algunas deficiencias por el uso ineficiente del espectro concesionado.

En diciembre de 1947, Donald H. Ring presentó la idea de la telefonía celular en AT\&T. El concepto fue elaborado dividiendo una ciudad en zonas llamadas células o celdas. Cada sitio de la célula tendría su propia antena y unidad transmisora-receptora. En el sistema MTS, por el contrario, había un solo transmisor grande para la mitad del área de cobertura y unos pocos receptores más pequeños, y en ciudades pequeñas solo un transmisor-receptor. Para evitar interferencias, cada célula utiliza frecuencias diferentes a las células vecinas. Sin embargo, un determinado conjunto de frecuencias puede

ISSN: 07 I8-2724. (http://www.jotmi.org)

Journal of Technology Management \& Innovation (c) Universidad Alberto Hurtado, Facultad de Economía y Negocios. 
ser reutilizado en muchas células en el área de cobertura. Este enfoque reduce el consumo de energía, lo cual hizo más fácil ampliar el servicio a nuevas áreas por las células de la adición y eliminar el problema de la debilidad de las señales hacia los bordes del área de cobertura. En la Figura I se muestra como se reutilizarían las frecuencias y como se conforman las células. No se introdujo este servicio celular entre los años 1940 ○ 1950 por la falta de capacidad computacional.

En esa época se empleaban las computadoras mainframe, las cuales no permitían su portabilidad por el gran tamaño y el alto consumo de energía, la informática sería necesaria en el desarrollo de los teléfonos celulares debido a que la tecnología celular requiere protocolos que eran complicados incluso para AT\&T, una compañía líder en telecomunicaciones.

Un invento fundamental para el desarrollo de la telefonía móvil fue el transistor. En diciembre de 1947 en Bell Labs, William Shockley, John Bardeen y Walter Brattain inventaron el transistor. En comparación con el equipo de tubos, los transistores permitían un tamaño más pequeño, menor consumo de potencia y mayor fiabilidad.

En la espera de las tecnologías necesarias Bell Labs proporcionó las bases para la telefonía celular. De esta manera, AT\&T se aseguraba de estar preparada para cuando la capacidad computacional llegase. En la búsqueda de esto, Bell Systems (Nombre de AT\&T que abarca diferentes empresas y filiales) solicitó a la Federal Communications Commission (FCC) en 1958, $75 \mathrm{MHz}$ de espectro en la banda de 800 $\mathrm{MHz}$, suficiente para dar cabida a miles de personas llamando simultáneamente. Esta solicitud estuvo en espera durante más de una década por no ser un servicio prioritario.
Para 1958 se daba otro avance, Jack Kilby en Texas Instruments y Robert Noyce en Fairchild Semiconductor, trabajando de forma independiente crearon el circuito integrado, que se convertiría en lo que hoy conocemos como el chip de silicio. A finales de la década de 1960 los chips de memoria de almacenamiento se estaban fabricando y se vendían comercialmente, poco después llegaron los microprocesadores, que actúan como pequeñas computadoras. Hoy en día un chip más pequeño que una moneda puede tener 125 millones de transistores y contienen toda la circuitería de un teléfono móvil.

Mientras tanto, AT\&T continuó haciendo modestas mejoras a su servicio de MTS, como marcación, selección automática de canales, canales duplex, reducción del ancho de banda para cada llamada y la reducción del costo de los equipos.

En 1968 las tres estrechas bandas de frecuencia asignadas a los teléfonos móviles se habían congestionado, la FCC revisó la solicitud del 958 de Bell Systems pero no estaban de acuerdo con el uso del espectro.

En 1969 un sistema de teléfonos móviles públicos se instalaron a bordo del Metroliner que recorría 362 kilómetros entre Nueva York y Washington D. C. La ruta se dividió en nueve zonas y las células con un conjunto diferente de frecuencias utilizadas en cada celda adyacente. El Departamento de Transporte de EE.UU. había solicitado este servicio para ayudar a promover el servicio de alta velocidad del ferrocarril interurbano Metroliner. Después de este éxito la FCC condicionó la aprobación de la concesión del espectro a AT\&T, si Bell Systems en dos años demostraba un sistema viable para automóviles. Fue entonces cuando AT\&T hizo todo lo posible para que esto ocurra $y$, un equipo se encargó de demostrar que la idea fuera factible con-

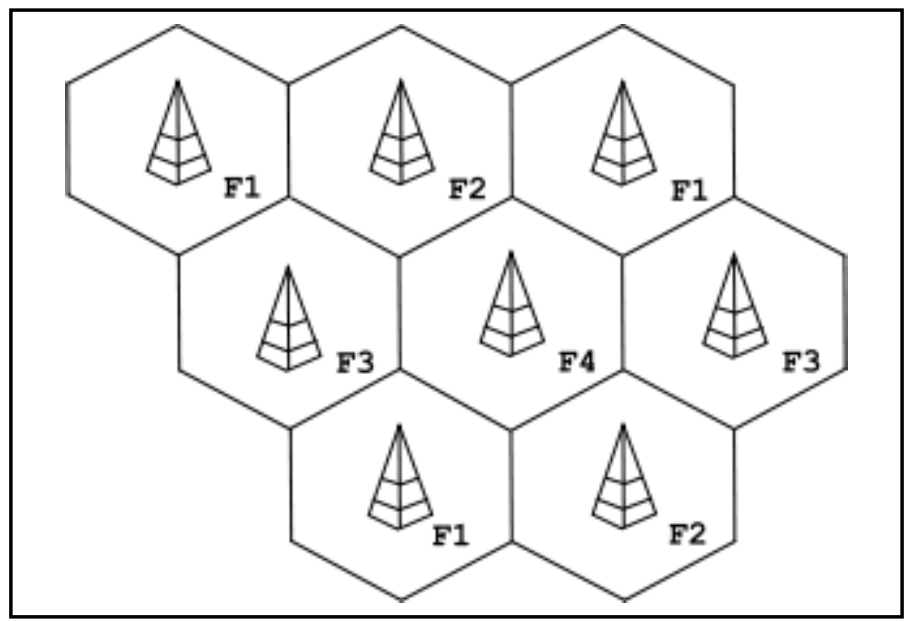

Figura I. Red de células. Fuente: Mier (2010)

ISSN: 07I 8-2724. (http://www.jotmi.org)

Journal of Technology Management \& Innovation (c) Universidad Alberto Hurtado, Facultad de Economía y Negocios. 
struyendo parte de los equipos de prueba. Entregaron un informe técnico a la FCC. El plan era que AT\&T obtenga ingresos con las llamadas de larga distancia, mientras que Motorola construiría el equipo, por razones de regulación y defensa de la competencia.

Con todos los nuevos desarrollos en la electrónica, la competencia por el espectro fue más feroz que nunca, si bien los teléfonos de automóvil no parecían una necesidad, cuando los microprocesadores llegaron al mercado (en 197I Intel lanza el procesador 4004) se hizo factible el teléfono móvil de mano. El primer prototipo de este aparato fue construido por AT\&T y Motorola en forma conjunta durante mucho tiempo.

Todo el mundo subestimó la demanda de teléfonos celulares en la creencia de que los ciudadanos comunes no necesitarían ni desearían utilizarlos. El 3 de abril de 1973, Motorola mostró el primer teléfono celular de mano. El teléfono utilizaba 14 chips de integración a gran escala, con miles de componentes en cada uno, algunos de ellos habían sido hechos a medida. No importaba que pesara cerca de un kilogramo o que la duración de la batería para una conversación fuera en minutos, el teléfono para ir a todas partes había sido finalmente construido. Motorola manifestaba que con la aprobación de la FCC, la ciudad de Nueva York podría tener un sistema celular de Motorola en 1976. Esa aprobación no llegó pero la demostración permitió que FCC estudiara la comunicación celular. Una comisión de la FCC pasó años redactando una serie de normas y reglamentos para la industria celular. Cada fabricante y proveedores tendrían que cumplir con las normas técnicas de la FCC. Esto retrasó la llegada de la tecnología celular pero hubo una gran ventaja para la compatibilidad.

AT\&T empezó a probar su primera red celular completa (pero no de mano) en julio de 1978 en Chicago. El sistema contaba con 10 celdas, cada una de aproximadamente un $\mathrm{Km}$ y medio de alcance y $\mathrm{I} 35$ vehículos con celulares. Esta red experimental demostró que un gran sistema celular podía trabajar. Ahora AT\&T requería la aprobación de la FCC con la asignación del espectro, pero esta tardó 4 años. Después de la separación de las compañías que conformaban AT\&T y con la asignación del espectro AT\&T comenzó a dar el servicio de telefonía móvil avanzado (Advanced Mobile Phone System - AMPS) el 12 de octubre de 1983. Bell System había invertido 500 millones de dólares desde 1969. Un mes más tarde Motorola lanzaría el sistema DynaTAC en Washington D.C.y Baltimore. En los siguientes tres años los dos sistemas operaban en los 90 mercados más grandes de Estados Unidos.

Sin embargo, con la desintegración oficial de AT\&T el I de enero de 1984, la empresa renunció voluntariamente a las licencias inalámbricas que operaban sus antiguas compañías telefónicas regionales, subestimando el potencial de la tecnología celular. En 1980 la corporación había encargado a McKinsey \& Company para predecir el uso de teléfonos celulares en el año 2000. El consultor había predicho 900000 abonados. Un error por un factor de 120, por el cual AT\&T pagó un alto precio.

A continuación la Tabla I presenta los hitos más importantes de la evolución de la radiotelefonía.

\begin{tabular}{|l|l|}
\hline Año & Hechos importantes \\
\hline 1919 & Radioteléfonos buque-tierra \\
\hline 1945 & AT\&T anuncia el radio-teléfono para automóviles \\
\hline 1947 & Donald H. Ring presentó la idea de la telefonía celular en AT\&T \\
\hline 1947 & En Bell Labs inventan el transistor \\
\hline 1958 & Bell Systems solicita a la FCC 75MHz de espectro en $800 \mathrm{MHz}$ \\
\hline 1958 & En laboratorios diferentes inventan y mejoran el circuito integrado \\
\hline 1960 & Se fabrican y venden comercialmente los chips de memoria \\
\hline 1968 & Las bandas asignadas para los teléfonos móviles eran insuficientes \\
\hline 1969 & Se instala el sistema de teléfonos móviles en el Metroliner \\
\hline 1971 & Intel lanza el primer microprocesador, el 4004 \\
\hline 1973 & Motorola muestra el primer celular de mano \\
\hline 1978 & AT\&T inicia las pruebas de una red celular vehicular en Chicago \\
\hline 1983 & AT\&T comienza a dar el servicio AMPS \\
\hline 1983 & Motorola instala DynaTac en Washington D.C.y Baltimore. \\
\hline
\end{tabular}

Tabla I. Evolución de la radiotelefonía. Fuente: Keith (2004a), Farley (2005)

ISSN: 07 I8-2724. (http://www.jotmi.org)

Journal of Technology Management \& Innovation (C) Universidad Alberto Hurtado, Facultad de Economía y Negocios. 


\section{Las tecnologías de la telefonía celular.}

Las tecnologías de la telefonía celular fueron desarrolladas en las últimas décadas (Farley, 2005). Debido a la subestimación de la demanda de celulares, por parte de los ciudadanos promedio, las redes de telefonía celular no se diseñaron para cargas altas, por lo tanto, las caídas en las llamadas eran comunes, para evitar ello, a fines de los 80 se aceleró la transición de sistemas analógicos a digitales, ya que digitalmente la transmisión es más eficiente, puede ser comprimida y requiere menos ancho de banda, además las señales digitales se pueden multiplexar, es decir, muchas señales pueden usar un canal que antes albergaba una sola señal analógica.

Este cambio a sistemas digitales comenzó en enero de 1989 , siendo el estándar elegido por la Telecommunications Industry Association la técnica de acceso múltiple por división de tiempo (Time Division Multiple Access - TDMA). Este servicio digital tenía simultáneamente la capacidad analógi$\mathrm{ca}$, aunque los teléfonos analógicos se estaban reduciendo (Belk, 2003; Farley, 2006; Mobileworld, 2008).

Para permitir más usuarios en el mismo espectro, la empresa Qualcomm de San Diego tuvo una solución con una técnica utilizada en aplicaciones militares llamada Code Division Multiple Access (CDMA). Para 1988, Qualcomm tenía sólo los conceptos y algunas patentes pero para finales de 1989 había demostrado con éxito un prototipo del sistema CDMA. En los siguientes años se instalaron los sistemas CDMA en otros países a la espera de la aprobación de EE.UU. la cual se dio en 1995. El sistema CDMA, al igual que su competencia TDMA, también daba cabida a los teléfonos analógicos existentes, que en ese momento eran más escasos (Farley, 2006).
A pesar de la digitalización, las redes de celulares volvieron a quedarse sin capacidad para más usuarios. El número de abonados llegó de 2 millones en 1988 a más de 16 millones para 1993 (Pearson Education, Inc., 2009). Era necesaria una mejor tecnología para solucionar este problema, pero no fue suficiente, así que se tuvo que licenciar un mayor espectro. La disponibilidad de nuevas frecuencias permitió otro sistema digital, el europeo Groupe Spéciale Mobile (GSM).

En Europa, en la década de 1980, se tenía nueve sistemas incompatibles de radiotelefonía analógica y las autoridades apostaron por un sistema digital, que se convirtió en un estándar para la mayor parte del mundo. Así el sistema GSM, introducido en 1991, ahora cuenta con cerca de mil millones de abonados.

Los sistemas celulares en EEUU presentan tres tecnologías por división de tiempo: TDMA (que ahora está retirada), GSM, Nextel (que se basa en tecnología patentada de Motorola, ahora conocido como iDEN) y la tecnología de Qualcomm CDMA que es el único sistema disponible en Estados Unidos que utiliza la división de códigos (Farley, 2006).

A principios del siglo $X X I$ los celulares se utilizan con una serie de servicios como descarga de tonos de llamada, envío de imágenes, mensajería de texto, juegos, correo electrónico, y hasta votaciones. A finales de la década del 2000 los celulares inician el uso del servicio de software de $\mathrm{Voz}$ sobre Protocolo de Internet (Voice over IP - VoIP) porque la capacidad de los procesadores de los celulares lo permitía. También hay planes para conectar de manera estándar redes WiMax y WiFi a las redes de celulares para expandir las comunicaciones (Stouffer, 2008; Edwards, 2009).

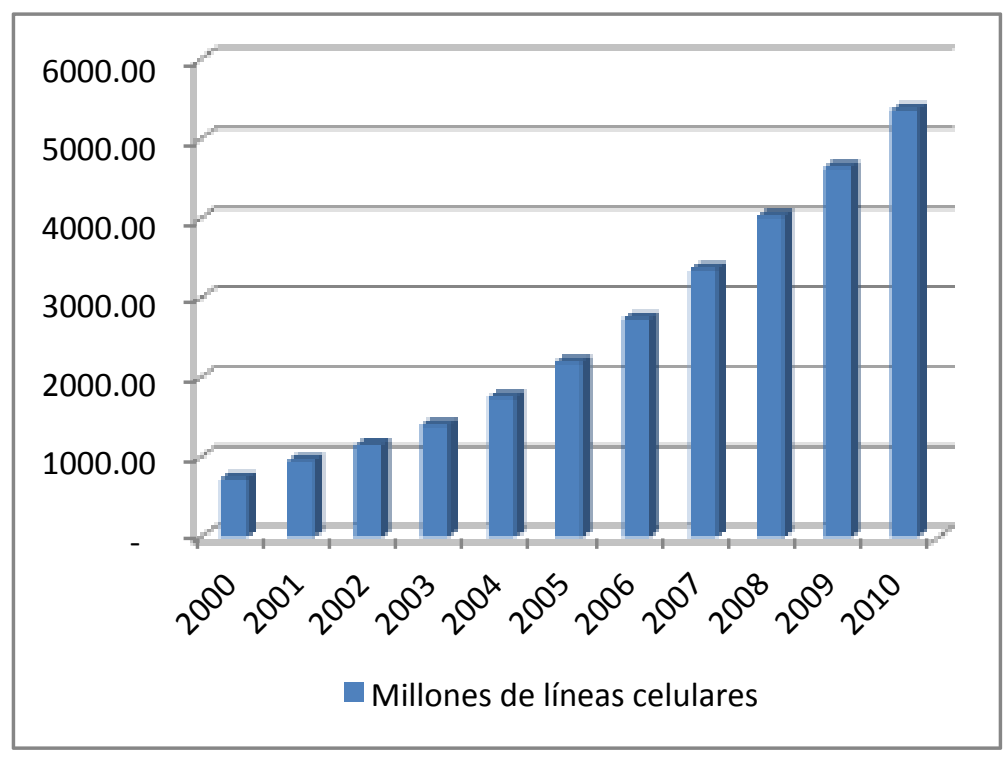

Figura 2. Número de líneas celulares en el mundo. Fuente: UIT (20I I)

ISSN: 07 I8-2724. (http://www.jotmi.org)

Journal of Technology Management \& Innovation (c) Universidad Alberto Hurtado, Facultad de Economía y Negocios. 
Por otro lado, hay también evolución en cuanto a las características de los celulares, estos se han vuelto más pequeños en los últimos años y se han fusionado con otros dispositivos dando origen a otros como el BlackBerry. Además, la inserción de la cámara en los equipos ha sido una de las mejoras más importantes desde su primer lanzamiento en el año 2000. Entre otras se puede mencionar el uso de baterías de Litio-ión, las cuales tienen una mayor duración gracias a lo cual no se necesita recargar en todo el día (Belk, 2003; Thanh, 2005; Webdesigner Depot, 2009). Todo ello implica una serie de ventajas para los usuarios.

\section{Estadísticas del mercado de telefonía celular}

En la última década el número de líneas de telefonía celular ha aumentado notablemente como se muestra en la Figura 2. Para el 2010 , según la UIT, a nivel mundial el número de suscripciones de telefonía celular sobrepasaba los cinco mil millones (UIT, 20I I).

Para el año 2010, como se muestra en la Figura 3, a nivel mundial el número de subscripciones de telefonía celular era cercano a 80 subscriptores por cada 100 habitantes, cantidad que sobrepasa a los usuarios de Internet y a los usuarios de las líneas telefónicas fijas.

De acuerdo con los analistas de IDC, que publican las estadísticas de distribución del mercado de teléfonos celular, se ha incrementado significativamente el volumen de celulares vendidos el primer trimestre del $201 \mathrm{I}$ con respecto al mismo periodo del 2010. Este primer trimestre se llegó a un total de 37I.8 millones de celulares. Después de los
5 proveedores más importantes, los vendedores en la categoría "Otros", tales como Micromax, TCL-Alcatel, Huawei, y Research In Motion tuvieron un crecimiento importante, el $46.4 \%$ en conjunto (IDC, $20 \mathrm{I}$ I).

La Tabla 2 muestra datos sobre la distribución del mercado de teléfonos celular, indicando la concentración en pocas empresas.

\section{La actividad de patentamiento}

El patentamiento promueve la invención porque una patente proporciona derechos de explotación a cambio de la publicación de lo inventado. Las patentes así como otros intangibles son estratégicos para las empresas, el cambio tecnológico y la innovación son factores importantes para la productividad y la competitividad y se han convertido en un tema central del análisis económico. Cada vez un mayor número de investigadores ha comenzado a utilizar las medidas basadas en las patentes (OECD, 2009).

El procedimiento de patentamiento está constituido por la presentación de una solicitud de la patente a la oficina nacional $o$ internacional de patentes, la asignación de un examinador por parte de la oficina de patentes y finalmente la concesión de la exclusividad de la explotación por un periodo de tiempo en caso sea aprobada la patente (OECD, 2009).

Las patentes son el indicador más ampliamente disponible de la producción de las actividades tecnológicas y constituyen una fuente muy valiosa de información sobre la distribución

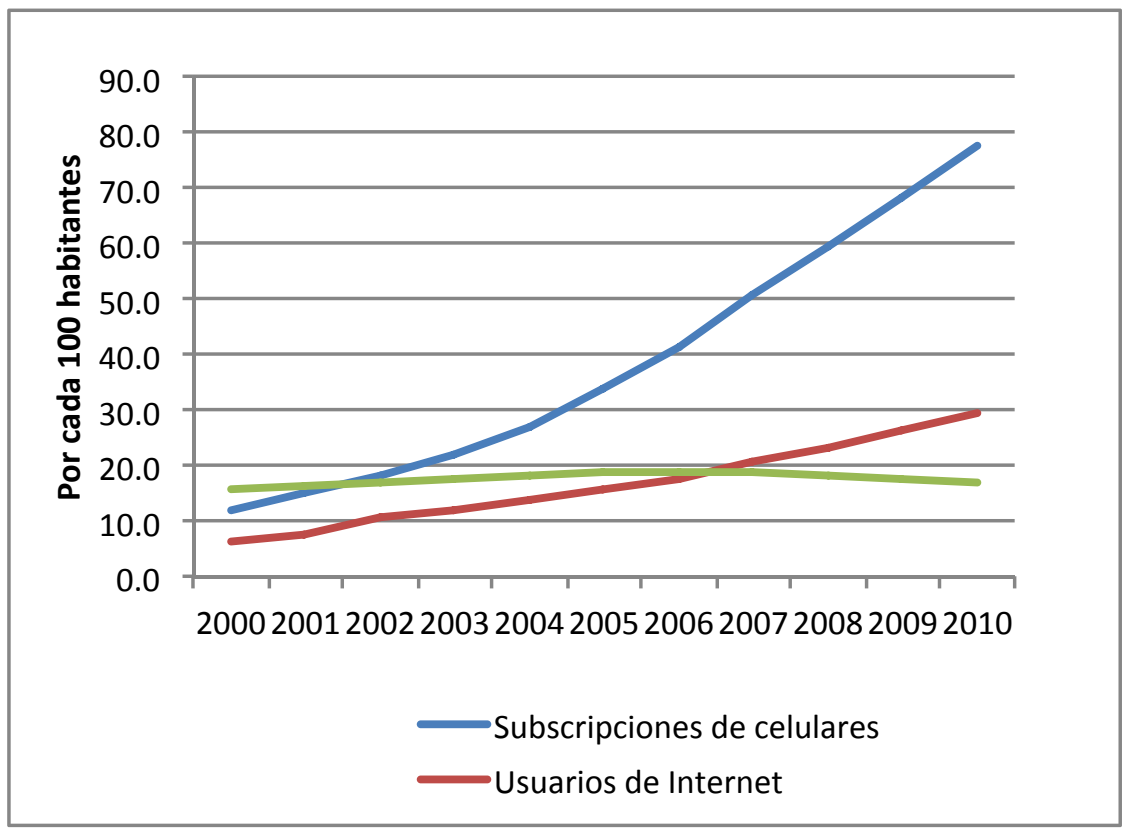

Figura 3. Estado de la telefonía celular a nivel mundial. Fuente: UIT (20II)

ISSN: 07 I 8-2724. (http://www.jotmi.org)

Journal of Technology Management \& Innovation (c) Universidad Alberto Hurtado, Facultad de Economía y Negocios. 
temporal, geográfica, sectorial y tecnológica de las invenciones. Las patentes representan el resultado del proceso inventivo, específicamente, de aquellas invenciones que se espera que tengan efectos comerciales, los cuales son un indicador particularmente adecuado para captar la dimensión de propiedad y la competencia de los cambios tecnológicos (Kürtössy, 2004).

Un documento de patente contiene la siguiente información: título, descripción abstracta y completa de la invención, el año de invención, el nombre, domicilio y nacionalidad del titular de la invención, las clase a la que pertenece la patente, y las citas de literatura científica y las patentes anteriores (Kürtössy, 2004; OECD, 2009).

Como cada vez los datos de las patentes están más disponibles de manera electrónica, un número de investigadores ha comenzado a utilizar las medidas basadas en las patentes y sus citas como indicadores de la producción tecnológica y de flujo de información (Kürtössy, 2004).

Por lo que respecta a la fuente de datos sobre patentes, tres tipos de proveedores de datos se pueden distinguir: oficinas individuales de patentes, las organizaciones internacionales y empresas comerciales (Kürtössy, 2004; OECD, 2009):

- Entre los organismos internacionales, la Organización Mundial de la Propiedad Intelectual (OMPI) que ha publicado las estadísticas sobre las solicitudes de patente y las patentes concedidas en todo el mundo desde 1979. La Oficina Europea de Patentes ha publicado los datos sobre solicitudes de patentes desde 1978.

- Las Oficinas nacionales de patentes como la de los Estados Unidos, que se utilizan para comparaciones entre países. El Inpadoc (Centro de Documentación Internacional de Patentes) ha construido una base de datos base con más de diez millones de patentes concedidas por $5 \mathrm{I}$ países que identifica las familias de patentes, es decir, grupos de patentes adoptadas en varios países para proteger a la misma invención (cuando una primera aplicación en un país - la prioridad - se amplía a otros oficinas).

- $\quad$ Entre las empresas comerciales está Derwent Publications Ltd., una empresa privada cuya actividad principal es la publicación de los resúmenes de patentes, ha creado un sistema para las estadísticas incluyendo datos cualitativos, que figura en los documentos de patente. Por otro lado, $\mathrm{CHI}$ Research, Inc. ha construido una base de datos, llamado Tech-Line $\AA$, en materia de patentes y las citas de patentes a nivel de los distintos países y empresas.

En la actividad de patentamiento se emplean generalmente los indicadores siguientes (OECD, 2009):

- Indicadores por el número de patentes: La mayoría de empresas tratan de buscar la protección de sus invenciones en EEUU, un indicador por empresa es el número de patentes que tiene registradas en EEUU otro podría ser el número de patentes por país según las clasificaciones y subclasificaciones para determinar en qué áreas se registra la actividad.

- Indicadores por el cambio porcentual de crecimiento: Estos indicadores están en función de los cambios porcentuales en la cantidad de patentes, indican la variación de la actividad I+D de una empresa, una región, un área tecnológica, etc.

- Otros indicadores que son más específicos y derivados de los indicadores anteriores: Fuerza de la tecnología, Fuerza de la Ciencia,Vinculación Científica, etc.

Como cualquier otra información disponible, un indicador en base a la información de las patentes también tiene ventajas y desventajas que se resumen a continuación (Kürtössy, 2004; OECD, 2009):

\begin{tabular}{|l|l|l|l|l|l|l|l|}
\hline Compañía & 2005 & 2006 & 2007 & Q3-2008 & Q3-2009 & Q3-20I0 & QI-20II \\
\hline Nokia & $31.8 \%$ & $34.1 \%$ & $38.6 \%$ & $39.4 \%$ & $36.5 \%$ & $32.4 \%$ & $29.2 \%$ \\
\hline Samsung & $12.3 \%$ & $\mathrm{II} .6 \%$ & $14.7 \%$ & $17.3 \%$ & $20.3 \%$ & $21.0 \%$ & $18.8 \%$ \\
\hline LG Electronics & $6.6 \%$ & $6.3 \%$ & $7.6 \%$ & $7.7 \%$ & $10.6 \%$ & $8.3 \%$ & $6.6 \%$ \\
\hline Apple & & & & & $2.5 \%$ & $4.1 \%$ & $5.0 \%$ \\
\hline ZTE & & & & & & & $4.1 \%$ \\
\hline Motorola & $17.5 \%$ & $21.3 \%$ & $12.8 \%$ & $8.5 \%$ & & & \\
\hline Sony Ericsson & $6.1 \%$ & $7.3 \%$ & $8.9 \%$ & $8.6 \%$ & & & \\
\hline R.I.M. & & & & & $2.9 \%$ & $3.6 \%$ & \\
\hline Otros & $25.6 \%$ & $19.4 \%$ & $17.4 \%$ & $18.5 \%$ & $27.2 \%$ & $30.5 \%$ & $36.3 \%$ \\
\hline
\end{tabular}

Tabla 2. Distribución del mercado de teléfonos celular. Fuente: IDC (2007), IDC (2008), IDC (20I0), IDC (20I I)

Nota: Para los años 2007 a 2010 se considera el porcentaje correspondiente al tercer trimestre del año y para el $20 \mathrm{II}$ al del primer trimestre.

ISSN: 07I 8-2724. (http://www.jotmi.org)

Journal of Technology Management \& Innovation (c) Universidad Alberto Hurtado, Facultad de Economía y Negocios. 


\section{Ventajas de la búsqueda de información en las patentes}

- $\quad$ La disponibilidad de los datos de oficinas de patentes es generalmente en series de tiempo muy largas.

- Los datos de patentes cubren prácticamente todos los campos de la tecnología, a excepción del software que generalmente está protegido por los derechos de autor.

- La información que está disponible sobre el tipo de tecnología, el inventor y mercados de referencia.

- La amplia gama de bases de datos informáticas desarrolladas por las instituciones y entidades comerciales que facilitan el acceso y manipulación de la información.

- La clasificación es muy detallada en los documentos de patentes.

- $\quad$ El tratamiento estadístico de los datos de la patente es en gran parte libre de errores, porque las patentes son documentos legales en los que los datos mencionados son cuidadosamente registrados.

Desventajas de la búsqueda de información en las patentes

- No todos los inventos son patentados, a veces las empresas protegen sus innovaciones con otros métodos como el secreto industrial, el lanzamiento rápido y precios bajos.

- Los factores institucionales como los derechos de patentes y procedimientos pueden variar de un país a otro. - $\quad$ El papel de las patentes en el proceso de la invención y la innovación no es el mismo para todas las empresas. - Existen diferencias en el comportamiento del patentamiento en todos los sectores, las instituciones de patentes, los mercados, tipos de los inventores y empresas.

Las patentes se encuentran clasificadas internacionalmente de acuerdo con la rama técnica que las incluye, existen ocho clases o secciones y se separan en subclases para poder comprender las diferentes actividades humanas (OEPM, 20II):
- $\quad$ Clase A: necesidades humanas.

- $\quad$ Clase B: técnicas industriales diversas, transporte.

- $\quad$ Clase C: química, metalúrgica.

- $\quad$ Clase D: textiles, papel.

- $\quad$ Clase E: construcciones fijas.

- Clase F: mecánica, iluminación; calefacción; armamento; voladuras.

- $\quad$ Clase G: física.

- $\quad$ Clase H: electricidad.

En particular, algunas de las subclases importantes relacionada a la industria de la telefonía celular es la H04 denominada "Técnica de las comunicaciones eléctricas". Como se describe en la Tabla 3 en esta subclase se encuentran las tecnologías para la industria de los teléfonos celulares, siendo la de más alto nivel de patentamiento, aunque no es la única subclase donde actúa esa industria.

\section{Metodología}

La presente investigación se centra en el análisis de la actividad de patentamiento en tres empresas del sector de equipos celulares. Se trata de un estudio de casos exploratorio para obtener información sobre la actividad de I+D que tienen estas compañías en los últimos años expresada a través del indicador de la cantidad de patentes y el análisis de las subclases donde la industria patenta. . El objetivo del trabajo es proporcionar un análisis comparativo de la evolución tecnológica de la industria de celulares en algunas empresas líderes seleccionadas. El estudio de caso está basado en Yin (1994) quien indica que esta metodología es usada cuando se busca responder a cuestiones de "cómo" y "por qué" con respecto al fenómeno abordado, el cual ocurre en el contexto de empresas de la industria de telefonía celular. Para poder investigar sobre la actividad de patentamiento de las empresas seleccionadas se usó la base de datos en línea que ofrece la OMPI, conocida como PATENTSCOPE. Esta

\begin{tabular}{|l|l|}
\hline H04B: & $\begin{array}{l}\text { TRANSMISIÓN } \\
\text { Descripción: Esta subclase hace referencia a equipos electrónicos que transmiten infor- } \\
\text { mación por medio de ondas electromagnéticas como es el caso de una estación de radio, } \\
\text { una celda de celular, en equipo celular, etc. }\end{array}$ \\
\hline H04L: & $\begin{array}{l}\text { TRANSMISIÓN DE INFORMACIÓN DIGITAL } \\
\text { Descripción: Esta subclase hace referencia a la transmisión de información en la forma como } \\
\text { la transmiten las computadoras, por medio de ceros y unos }(0 \text { y I) que es el caso de los } \\
\text { celulares digitales, radios digitales, televisores digitales, etc. }\end{array}$ \\
\hline H04M: & $\begin{array}{l}\text { COMUNICACIONES TELEFÓNICAS (circuitos para el control de otros } \\
\text { Descripción: Esta subclase hace referencia a los dispositivos adicionales requeridos para } \\
\text { establecer las comunicaciones telefónicas como las celdas de celulares pero no las centrales } \\
\text { telefónicas por ser de conmutación telefónica. }\end{array}$ \\
\hline
\end{tabular}

Tabla 3. Muestra de subclases de la clase H04. Fuente: OEPM (20I I)

ISSN: 07 I8-2724. (http://www.jotmi.org)

Journal of Technology Management \& Innovation (c) Universidad Alberto Hurtado, Facultad de Economía y Negocios. 
permite hacer una búsqueda de acuerdo con ciertos criterios que se especifiquen en la sintaxis soportada por el motor de búsqueda. Por ejemplo la solicitud "ALLNAMES:(nokia) DP: 200I" indicaría hacer una búsqueda de las patentes que arroje como resultados aquellas patentes que contienen en los nombres la cadena "nokia" y cuya fecha de presentación fue el $200 \mathrm{I}$.

Existen otras alternativas a PATENTSCOPE, una similar y también de libre uso limitado con su propia sintaxis de búsqueda es ESPACENET. Las demás alternativas son pagadas desde el uso limitado como los servicios de búsqueda y análisis de patentes de Thomson Reuters, Derwent Publications y otras. Estas empresas en la actualidad ofrecen también sus servicios en línea. Los servicios limitados permiten descargar las patentes en grupos pequeños, por ejemplo cada 10 patentes, y si en una búsqueda se obtienen miles de patentes se deberán hacer muchas acciones repetitivas manualmente para descargar toda la información.

Para reducir los errores y el tiempo que tomaría la tarea manual de descargar las patentes, se puede pagar por un servicio de descarga de patentes que como en el caso de Thomson Reuters tiene costos de subscripción mensual y por la descarga por cada 500 patentes. Otra alternativa es desarrollar un aplicativo para descargar de manera automática las patentes de los servicios gratuitos, por grupos pequeños, la cual fue la opción elegida en la presente investigación.

Para poder automatizar la descarga de las patentes se desarrolló un conjunto de scripts en Perl y se ejecutaron sobre una computadora con la distribución de Linux CentOS, el funcionamiento de estos scripts se representan mediante el diagrama de flujo de la Figura 4. Al ejecutar los scripts se desempeña las mismas tareas que serían manuales si no se contasen con ellos para descargar la información de las patentes. Estos scripts requieren que se ingrese el nombre de la empresa, el año y la cantidad de patentes que descargará en cada operación del bucle. Con estos datos la aplicación se encarga de la generación del URL, descargar las patentes y el guardado de las mismas en la base de datos.

Para poder hacer las comparaciones entre las diferentes empresas a nivel del perfil del patentamiento se utilizó el análisis de correspondencias, que es una técnica descriptiva desarrollada por Jean-Paul Benzécri y permite analizar más de dos variables en un plano, escalando las correspondencias de los datos entre filas y columnas.

"El Análisis de Correspondencias es una técnica estadística que se aplica al análisis de tablas de contingencia y construye un diagrama cartesiano basado en la asociación entre las variables analizadas. En dicho gráfico se representan conjun- tamente las distintas modalidades de la tabla de contingencia, de forma que la proximidad entre los puntos representados está relacionada con el nivel de asociación entre dichas modalidades." (Salvador, 2003). Este análisis puede emplearse para correspondencias simples:"Este procedimiento se aplica a tablas de contingencia bidimensionales en las que se encuentran implicadas dos variables, $X$ e $Y$ con sus respectivas categorías, P y q denominadas modalidades." (RUA, 20I I) o también para correspondencias múltiples: "Este procedimiento se presenta como extensión de la técnica anterior al caso de más de dos variables." (RUA, 20II).

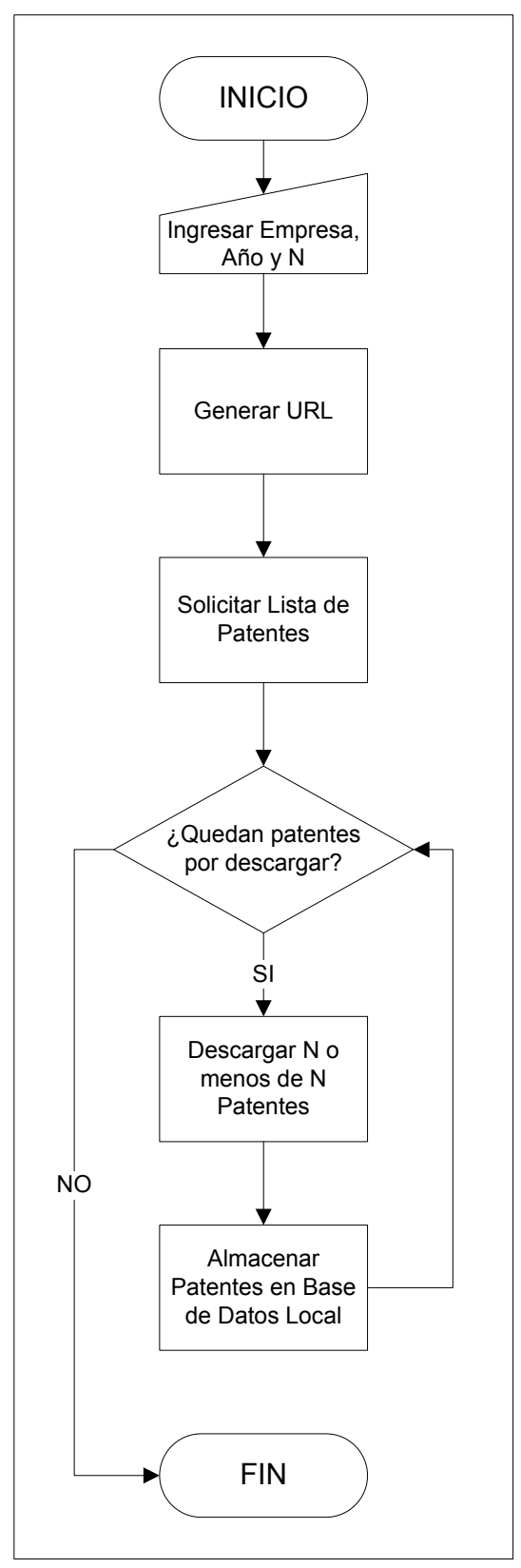

Figura 4. Diagrama de flujo de la descarga de patentes

ISSN: 07 I8-2724. (http://www.jotmi.org) 
El análisis de correspondencia puede ser aplicado usando diferentes herramientas informáticas, entre ellas se encuentra el programa SPSS, cuyo actual titular es IBM, este es el programa que se utilizó para el presente trabajo de investigación.

Para este estudio se procesaron los resultados en los que priorizan las diez subclases de patentes más importantes independientemente por cada empresa, por ser las más significativas y en los análisis se incluyen las clases que contengan mayor número de patentes. El trabajo se realizó sobre los años 2001 al 2010 dentro de los que se cuenta adicionalmente con algunos informes económicos de las empresas de la industria de celulares.

Finalmente, con los resultados de correspondencia y los volúmenes de patentamiento se hicieron comparaciones con los resultados económicos y participación de mercado de cada una de las empresas y en conjunto. Cabe indicar que, para la comparación de la actividad de I+D en función del patentamiento y el análisis de correspondencia, se ha considerado incluir los datos de otras empresas que lideran esta industria tales como APPLE, LG, SAMSUNG para poder establecer una mejor comparación.

\section{Estudios de caso}

La investigación se centra en las empresas Nokia, Huawei y ZTE. Nokia se seleccionó por encontrarse en el primer lugar de ventas en los últimos años, Huawei por ser mencionada en diferentes artículos del sector por ser un proveedor de teléfonos celulares y equipos para las redes de celulares y ZTE porque ha llegado al grupo de las cinco primeras en los últimos periodos evaluados según IDT.A continuación se presenta una breve reseña de estas tres empresas.
Nokia Corporation es una empresa pública que opera a nivel global y cotiza en bolsa, fabrica y vende dispositivos móviles, proporciona servicios de cartografía digital y navegación por Internet en todo el mundo. Fue fundada en I865. Actualmente opera en 150 países del mundo y tiene su sede principal en Espoo, Finlandia (YAHOO FINANCE, 20I IA; PLUNKETT RESEARCH, 20 I IB).

Huawei es un proveedor de soluciones de telecomunicaciones. A través de una continua innovación centrada en el cliente atiende a los proveedores y usuarios de las redes. La innovación de la empresa se centra en el uso de diversos medios de comunicación como la voz, el fax, el correo electrónico, la web, el vídeo, SMS, WAP, MMS, etc. estableciendo un eficiente canal de comunicación para la atención al cliente, el marketing y las ventas. En el mercado global de las tecnologías de telefonía fija, móvil e IP, Huawei ha ganado una posición de liderazgo, sus productos y soluciones se han desplegado en más de 140 países y venden al $90 \%$ de los principales operadores de telecomunicaciones del mundo, así como a la tercera parte de la población mundial. El 9 de julio de 2010 , Huawei alcanzó por primera vez el "Fortune Global 500”. Además tiene previsto invertir alrededor de US $\$ 500$ millones en Tamil Nadu, India (HUAWEI TECHNOLOGIES CO., LTD., 20I I). Las soluciones de la compañía se han desplegado en más de 100 países. Huawei tiene su sede en Shenzhen, China y opera en Latinoamérica con oficinas en Chile, Brasil, Perú y Venezuela, entre otros países (BUSINESS NEWS AMERICAS, 20I I).

ZTE Corporation fundada en 1985, es la compañía china más grande de equipos de telecomunicaciones, cotiza en las bolsas de Shenzhen y de Hong Kong y provee de equipos de telecomunicaciones y soluciones de redes que operan en más

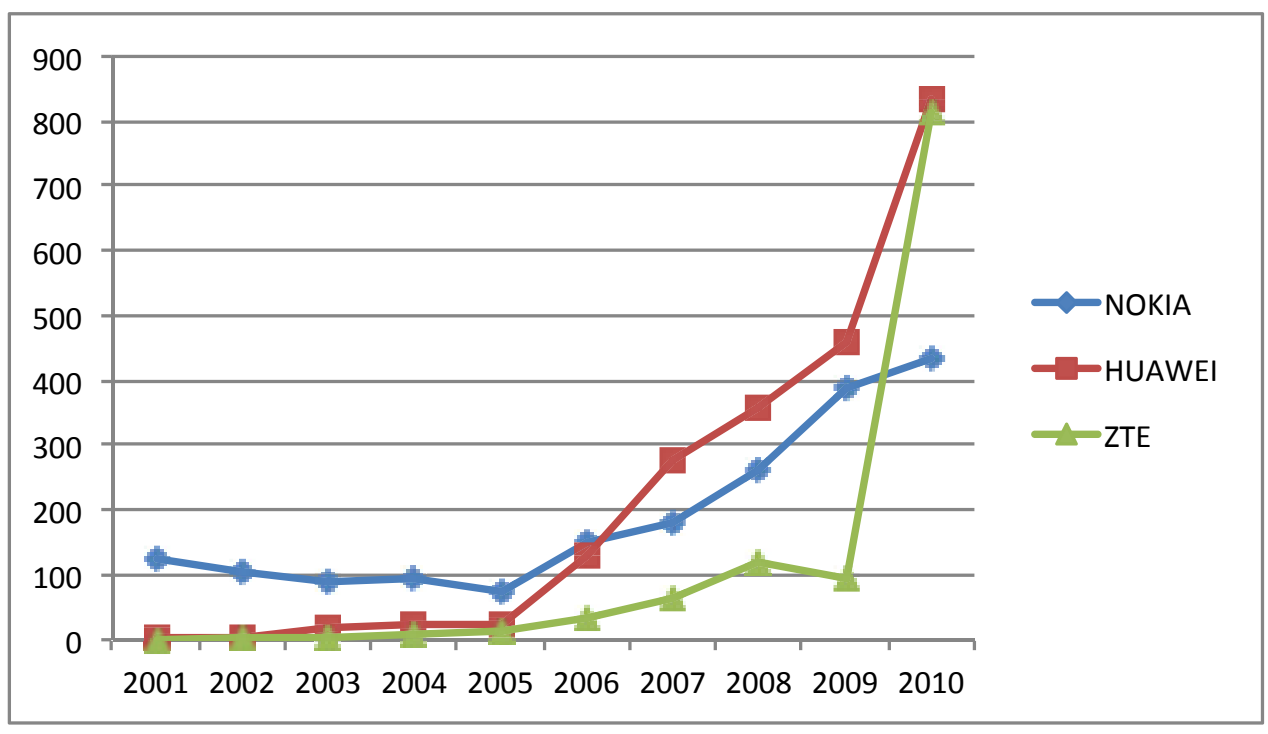

Figura 5. Patentes en la subclase H04W por NOKIA, HUAWEI y ZTE. Fuente: OMPI (20I I)

ISSN: 07I 8-2724. (http://www.jotmi.org)

Journal of Technology Management \& Innovation (c) Universidad Alberto Hurtado, Facultad de Economía y Negocios. 
de I 40 países. Ofrece una amplia variedad de productos que van desde voz, datos, multimedia y servicios inalámbricos de banda ancha. (ZTE CORPORATION, 20II). Sus oficinas principales se encuentran en China; sin embargo, cuenta con centros de investigación en otros países como EEUU y ha establecido vínculo comercial con más de 500 operadores en todo el mundo (YAHOO FINANCE, 20l l b).

En la Figura 5, se puede observar que la actividad de patentamiento de las empresas Huawei y ZTE tiene un aumento notorio en los últimos años en el caso de la subclase H04W, correspondiente a redes de comunicación inalámbrica:

Con respecto a la actividad de patentamiento considerando las diez subclases más representativas a cada empresa por cada año, entre las importantes están G0IS, H04N, H04R, G06Q, GI0L, H04M, H04B, G06F, H04L, H04W. Por otro lado, podemos observar, en la Figura 6, que ZTE ha alcanzado en el número de patentes por año a NOKIA.Y actualmente HUAWEl supera en número de patentes por año a NOKIA. Los picos y caídas se deben principalmente a que los negocios TIC dependen de la situación financiera del mundo (IDC, 2008) y en el 2008 se presentó una de las mayores crisis financieras del mundo.

En la Figura 7 se muestra que la actividad de patentamiento de las empresas SAMSUNG y LG, que se encuentran dentro de los fabricantes líderes, también se ha reducido en los últimos años y las que estarían en incremento de su actividad I+D sería las compañías HUAWEl y ZTE.

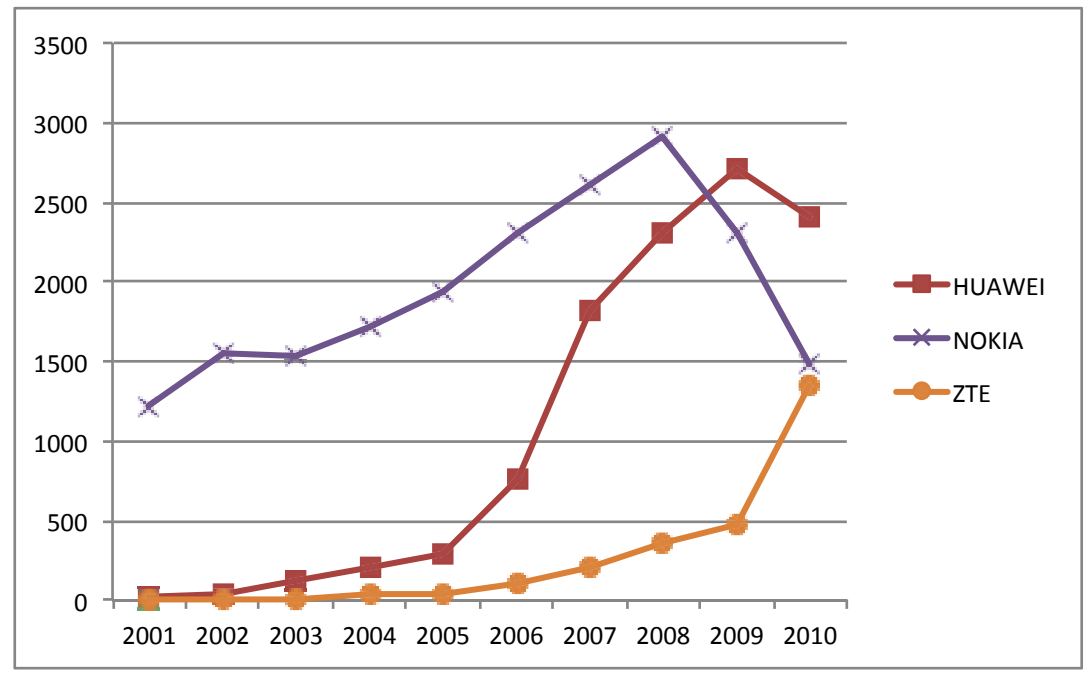

Figura 6.Actividad de patentamiento de NOKIA, HUAWEl y ZTE. Fuente: OMPI (20II)

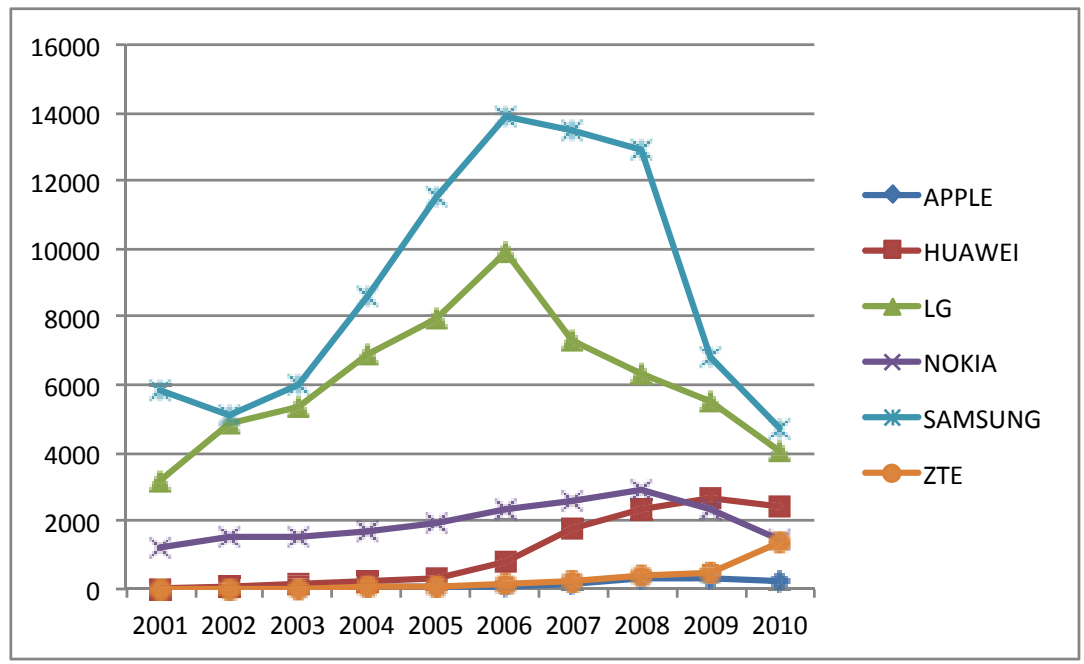

Figura 7.Actividad de patentamiento de los principales actores del sector. Fuente: OMPI (20II)

ISSN: 07 I8-2724. (http://www.jotmi.org)

Journal of Technology Management \& Innovation (c) Universidad Alberto Hurtado, Facultad de Economía y Negocios. 
En la Figura 8, se aprecian los resultados económicos de las tres empresas consideradas para el estudio, estos resultados guardan relación específicamente con las ventas. Donde el coeficiente de Pearson es de 0.83 a diferencia del correspondiente a las utilidades de 0.09 , después de analizar los datos por medio de la correlación de Pearson para la actividad de patentamiento de la Figura 6 y los resultados económicos de la Figura 8. Cabe mencionar que existen también otros factores que influyen en los resultados como las características visuales, precio, plataforma, etc. y el marketing que se realice.

En la Figura 9 se muestra el patentamiento por subclase de las tres empresas en estudio en su conjunto y de esta figura podemos observar que los mayores avances tecnológicos en la última década y en lo que va del 201 I se han dado en las siguientes subclases ordenadas de acuerdo al volumen de patentes en la Tabla 4.

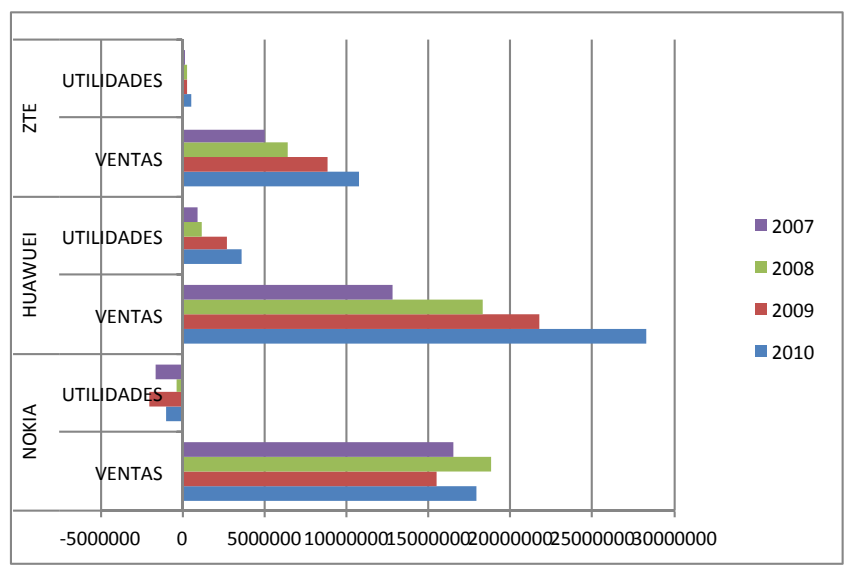

Figura 8. Resultados económicos de los principales actores del sector. Fuente: Plunkett Research (20 I la), Plunkett Research (20I Ib), Plunkett Research (20I Ic)
Comparando las diferentes subclases de la Tabla 4 podemos indicar que las características que se mejorarán en los celulares y que serán perceptibles por los usuarios pertenecen a las subclases H04N y G I OL, que podrían ser por ejemplo la transmisión de video en vivo y los comandos por voz.

Tras haber realizado el análisis de correspondencias de las empresas APPLE, HUAWEI, LG, NOKIA, SAMSUNG, ZTE con las cantidades de patentes publicadas de las 10 subclases más representativas de cada una de ellas entre los años $200 \mathrm{I}$ al 2010, año por año y del periodo en su totalidad, se obtuvieron los gráficos que se presentan desde la Figura 13 a la Figura 23. De estos se desprende que las empresas Nokia, ZTE y Huawei presentan un perfil de patentamiento semejante, están investigando las mismas tecnologías y estarían participando del mismo sector en los siguientes años.

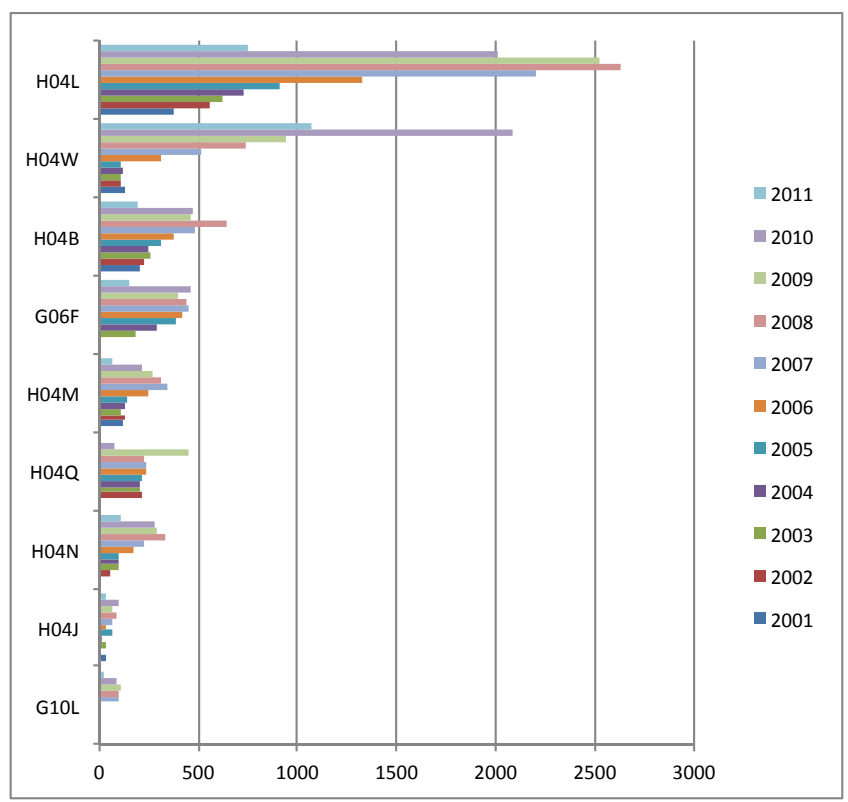

Figura 9. Patentamiento por subclases. Fuente: OMPI (20II)

\begin{tabular}{|l|l|}
\hline H04L & TRANSMISION DE INFORMACION DIGITAL \\
\hline H04W & REDES DE COMUNICACION INALAMBRICAS \\
\hline H04B & TRANSMISION \\
\hline G06F & TRATAMIENTO DE DATOS DIGITALES ELECTRICOS \\
\hline H04M & COMUNICACIONES TELEFONICAS \\
\hline H04Q & SELECCIÓN \\
\hline H04N & TRANSMISION DE IMÁGENES \\
\hline H04J & COMUNICACIONES MULTIPLEX \\
\hline GI0L & $\begin{array}{l}\text { ANALISIS O SINTESIS DE LA VOZ; RECONOCIMIENTO DE LA VOZ;ANALISIS O } \\
\text { TRATAMIENTO DE SEÑALES DE AUDIO }\end{array}$ \\
\hline
\end{tabular}

Tabla 4. Principales subclases en las que se patenta en el sector. Fuente: OMPI (20I I)

ISSN: 07 I8-2724. (http://www.jotmi.org)

Journal of Technology Management \& Innovation (c) Universidad Alberto Hurtado, Facultad de Economía y Negocios. 
En las Figuras 10 y II se muestran los resultados del análisis para los años 2001 y 2002 respectivamente, las empresas NOKIA, HUAWEl y ZTE presentan un perfil de patentamiento similar, pero adicionalmente Samsung y LG está muy cerca a estas en el 2001 y 2002 respectivamente. Samsung y LG son principales participantes del mercado de celulares por lo que lideran también la actividad I+D de este sector, en la Tabla 2 se mostró a los principales actores del mercado de equipos celulares.

En la Figura 12 se muestran los resultados del análisis para el año 2003, las empresas en estudio también presentan un perfil de patentamiento similar, en este caso Apple está muy cerca a estas. Esto tiene relación con el ingreso de Apple al mercado de telefonía en los siguientes años con el IPhone (Penalva, 2007)

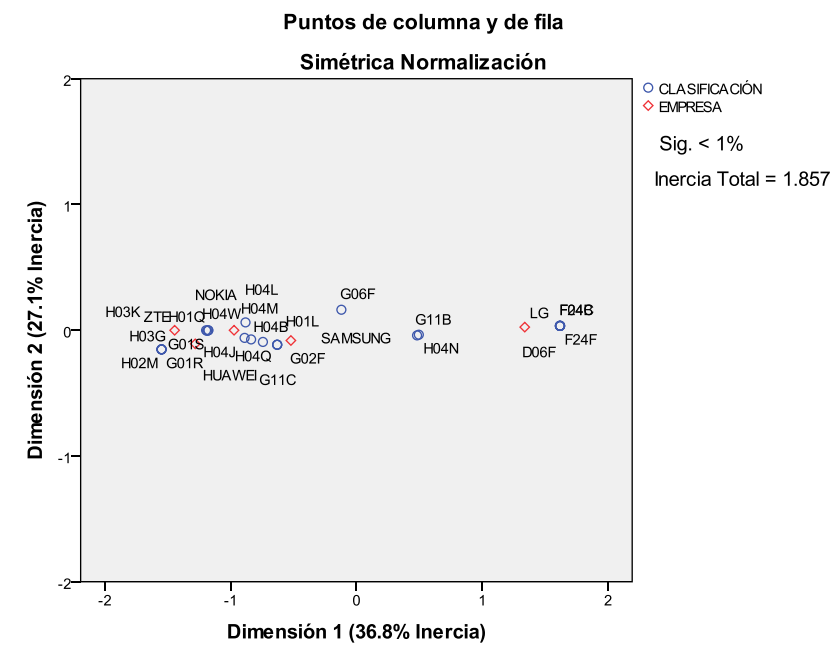

Figura I0. Resultados del 200I. Fuente: OMPI (20II)

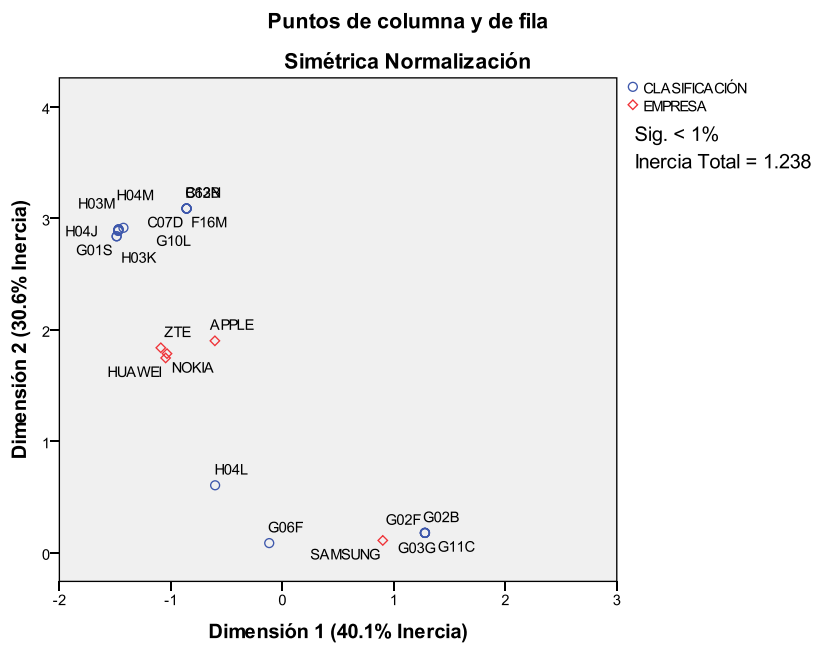

Figura I2. Resultados del 2003. Fuente: OMPI (20I I)
En la Figura 13 se muestran los resultados del análisis para el año 2004, las empresas en estudio también presentan un perfil de patentamiento similar, en este caso como en los resultados del 2002 LG está muy cerca a estas.

En la Figura 14 y la Figura 15 se muestran los resultados del análisis para los años 2005 y 2006 respectivamente, las empresas en estudio también presentan un perfil de patentamiento similar en ambos casos.

En las figuras 16, 17, 18 y 19 se muestran los resultados del análisis para los años 2007, 2008, 2009 y 2010 respectivamente. Las empresas en estudio también presentan un perfil de patentamiento similar. En algunos casos están con un perfil cercano Apple, Samsung y LG, actores principales del mercado indicados anteriormente en la Tabla 2.

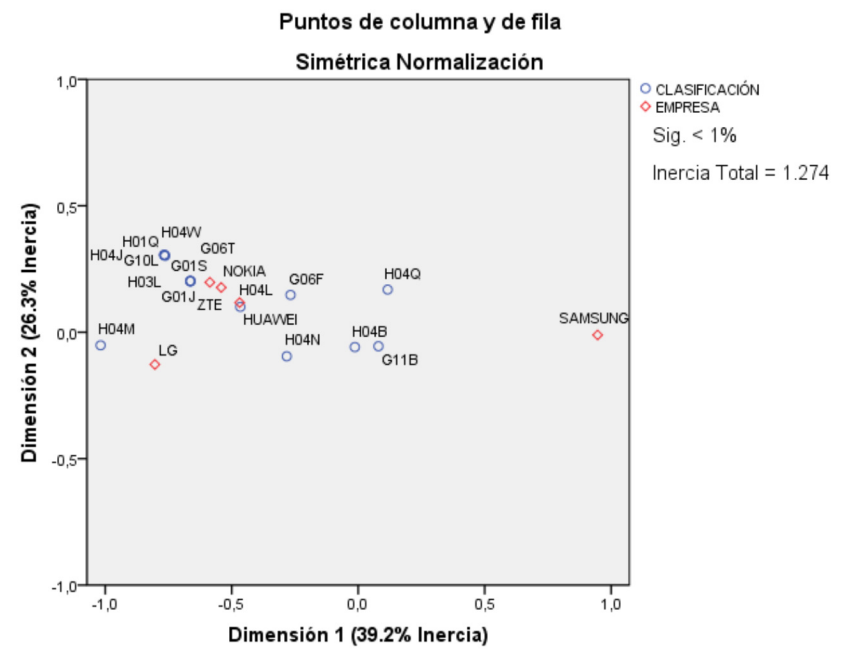

Figura II. Resultados del 2002. Fuente: OMPI (20I I)

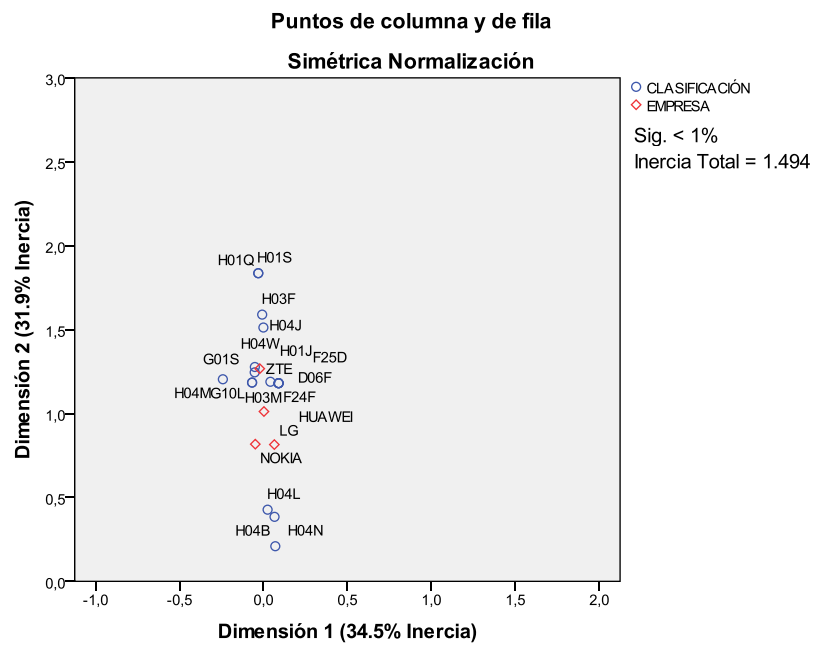

Figura I3. Resultados del 2004. Fuente: OMPI (20I I)

ISSN: 07 I8-2724. (http://www.jotmi.org) 


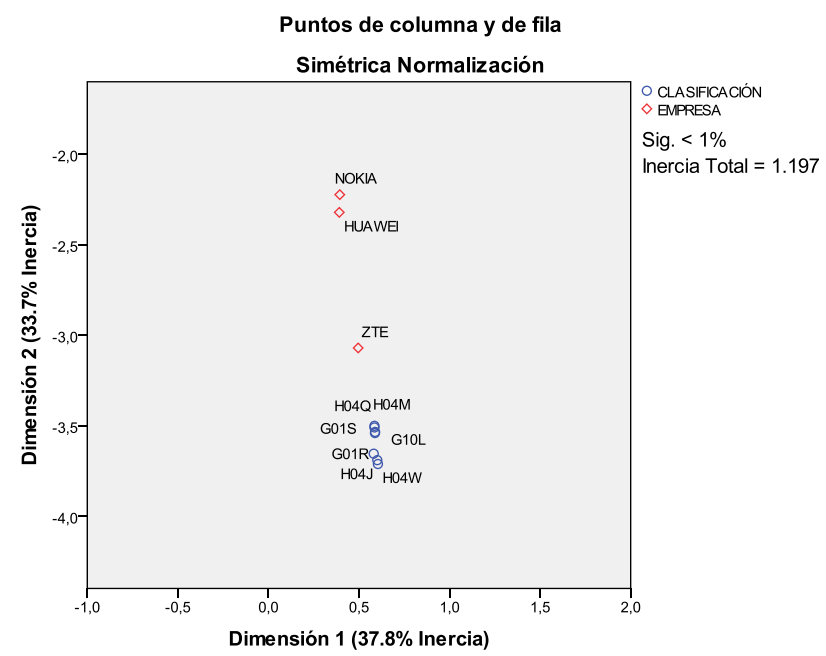

Figura I4. Resultados del 2005. Fuente: OMPI (20II)

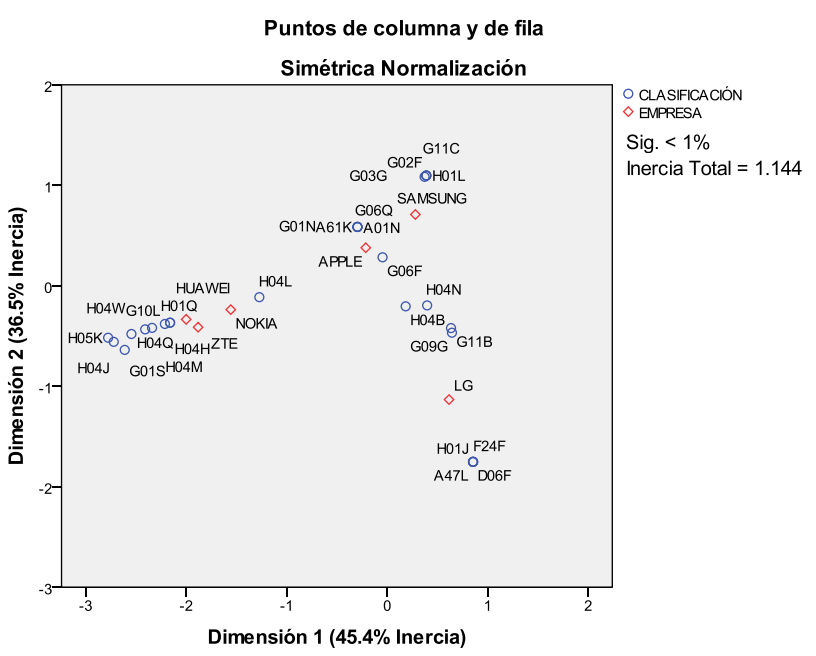

Figura 16. Resultados del 2007. Fuente: OMPI (201I)

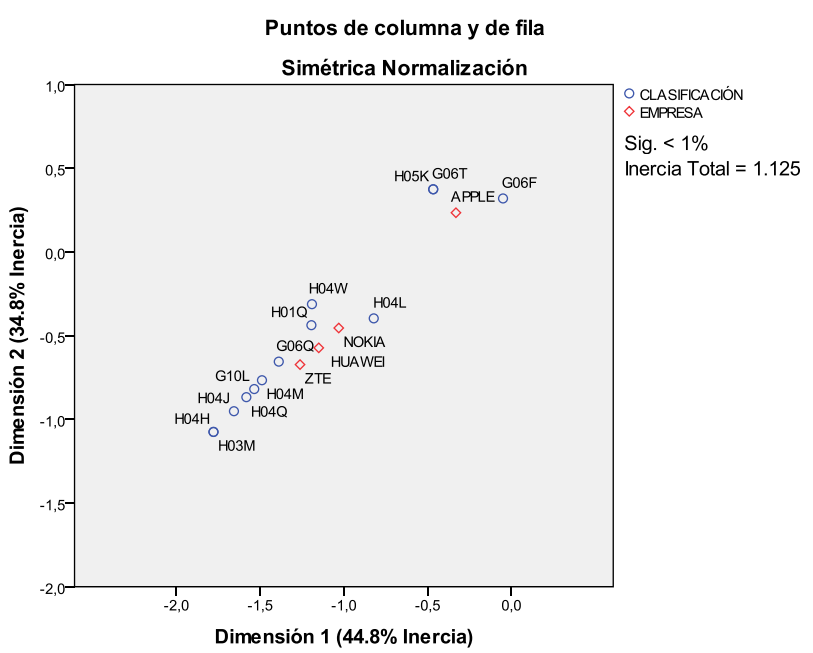

Figura 18. Resultados del 2009. Fuente: OMPI (20I I)

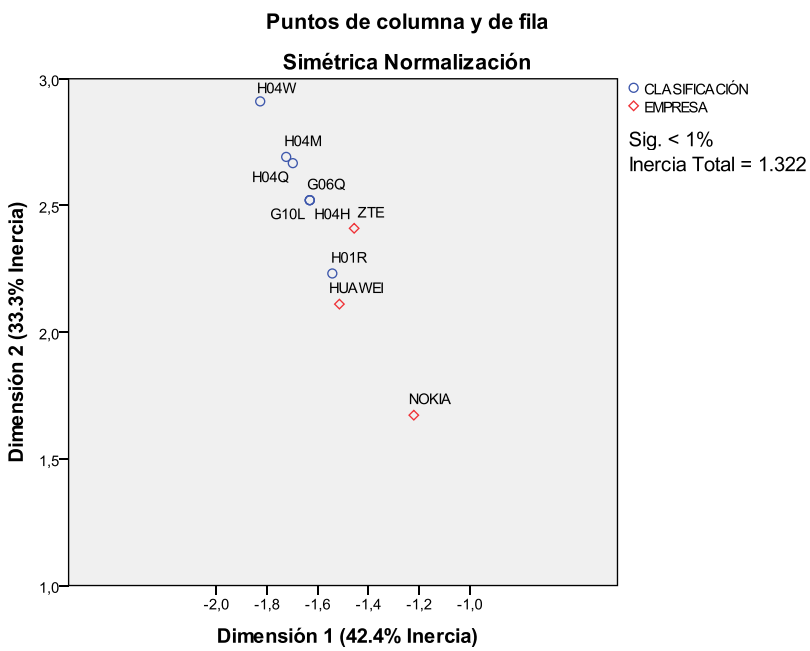

Figura I5. Resultados del 2006. Fuente: OMPI (20I I)

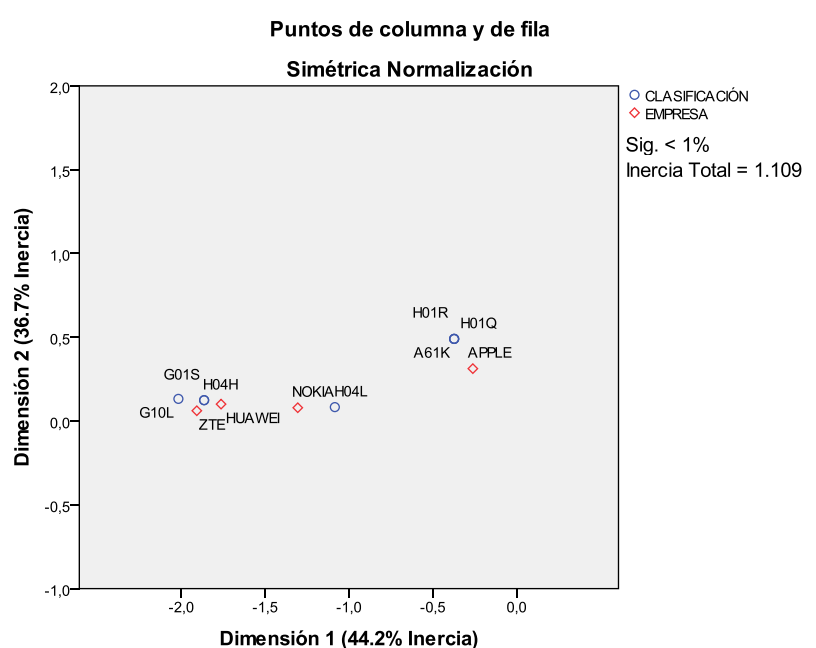

Figura I7. Resultados del 2008. Fuente: OMPI (20I I)

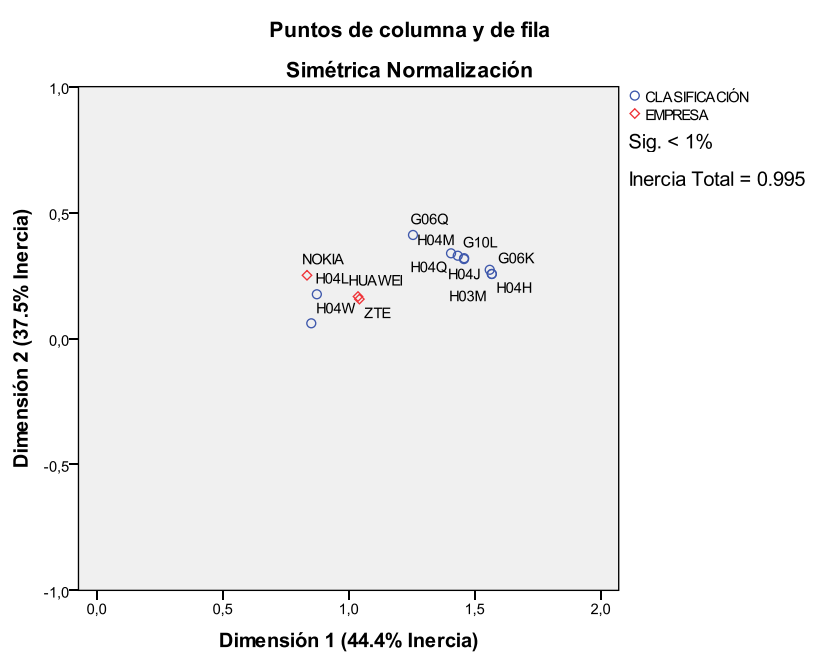

Figura 19. Resultados del 20I0. Fuente: OMPI (20II)

ISSN: 07 I8-2724. (http://www.jotmi.org)

Journal of Technology Management \& Innovation (c) Universidad Alberto Hurtado, Facultad de Economía y Negocios. 
En la Figura 20 se muestran los resultados del análisis de los años 2001 al 2010, las empresas en estudio presentan un perfil de patentamiento similar, y aparecen con resultados cercanos Samsung y LG, participantes importantes del mercado, indicados anteriormente en la Tabla 2.

\section{Conclusiones}

En esta investigación se ha considerado a la actividad de patentamiento como un indicador la actividad de I+D de la empresa. En este sentido, se ha empleado este indicador buscando una correlación con los resultados de ventas de las empresas en estudio, encontrándose buena correlación a través del coeficiente de Pearson.

Sin embargo, la actividad de I+D no necesariamente garantiza el éxito, tal es el caso de Nokia, que a pesar de invertir en I+D no tuvo utilidades en los últimos periodos a pesar de unas ventas altas, debido a que el mercado también depende de otros factores como las preferencias de los usuarios. Nokia optó por Windows para sus teléfonos más avanzados mientras que los otros fabricantes optaron por Android, y los usuarios tienen mayor preferencia por Android (IDC, 20II).

Si una empresa sigue el mismo perfil de patentamiento que los líderes del mercado, sería factible que también llegue a liderar el mercado en el futuro, como en el caso de ZTE, que después de varios años de desarrollar actividad de I+D en la misma dirección de Nokia logra aparecer entre los cinco líderes del mercado en el $201 \mathrm{I}$.

Las empresas Samsung, LG y Apple tienen el perfil de patentamiento similar a las empresas en análisis en algunos años debido a que estas son líderes en el sector de equipos de telefonía celular y también están investigando en las líneas de sus mayores competidores para mantenerse en el mercado. El análisis de correspondencias de los casos seleccionados nos ha permitido descubrir que estaban orientados en la misma actividad I+D dentro de esta industria, es decir, están siguiendo las mismas líneas de investigación. De extender el presente estudio trabajando con detalles más específicos de los incluidos en las mismas patentes y aplicando técnicas como la de minería de datos, se podría llegar a describir las tendencias de las características nuevas de los equipos celulares que se lanzarán al mercado en los siguientes periodos. La simetría de la actividad de patentamiento encontrada con el análisis de correspondencia sustenta que las empresas ZTE y HUAWEI siguieron inicialmente al líder del mercado NOKIA en las mismas líneas de investigación y en los últimos años han superado el número de patentes del líder en esos campos tecnológicos.

Es factible desarrollar herramientas de descarga y análisis de patentes con una inversión pequeña, en el caso de este proyecto se usó software libre para escribir los scripts de descarga, ahorrando el pago de licencias por las herramientas de desarrollo.

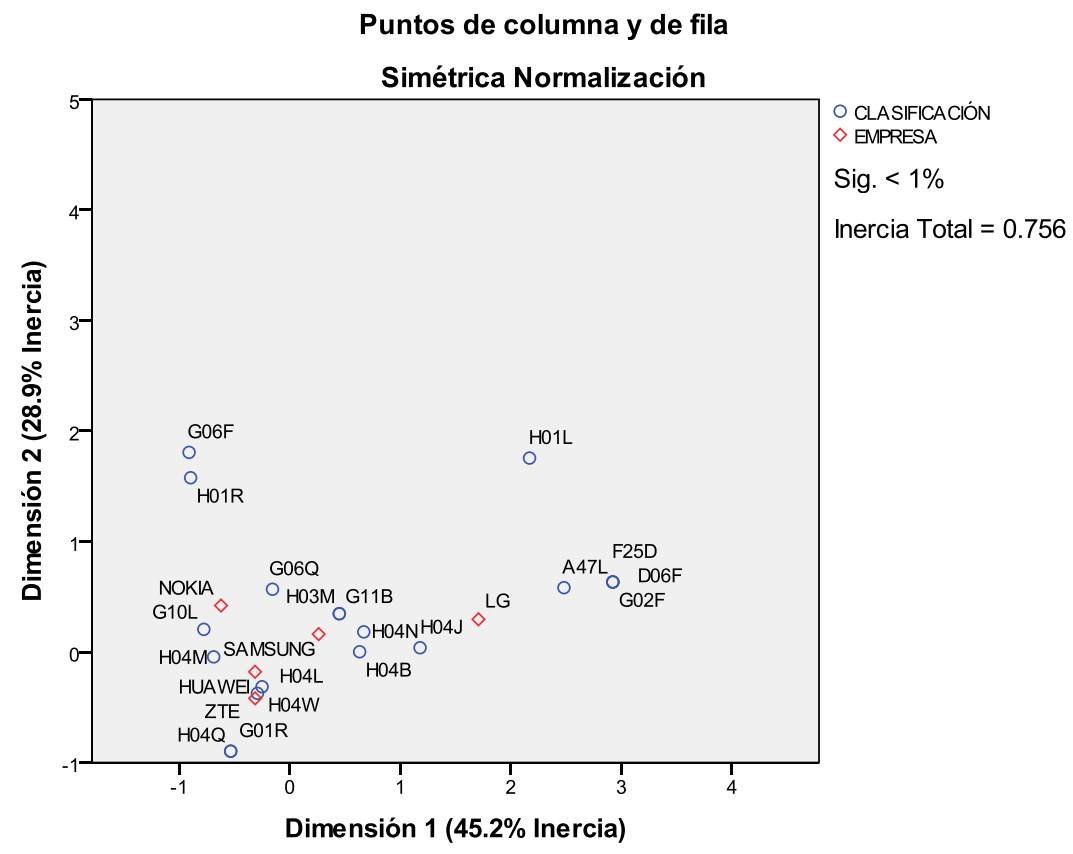

Figura 20. Resultados del $200 \mathrm{I}$ al 20I0. Fuente: OMPI (20I I)

ISSN: 07I 8-2724. (http://www.jotmi.org)

Journal of Technology Management \& Innovation (c) Universidad Alberto Hurtado, Facultad de Economía y Negocios. 
Es posible hacer análisis de patentes usando bases de datos públicas limitadas si el número de patentes a analizar es bajo, de lo contrario se tendrá que hacer uso de un servicio pagado o automatizar de alguna forma la descarga de patentes para reducir los tiempos de las tareas que serían manuales y repetitivas.

En el sector de equipos celulares se seguirá (Pinto, 20I I) los volúmenes de ventas en el futuro por la tendencia del crecimiento de usuarios y la tendencia a adquirir equipos más sofisticados, como es el caso de los teléfonos con Android y Windows.

\section{Bibliografía}

ALIBABA GROUP (20lla). Advanced Search android+ZTE+Huawei. Alibaba.com http://www.alibaba. $\mathrm{com} /$ trade/search?SearchText=android $+Z T E+$ Huawei\&ad vancesearch $2=$ Search\&opt $=O R \&$ IndexArea=product_en [Consultado el 20 de Julio de $20 \mathrm{II}$ ].

ALIBABA GROUP (20l lb). Advanced Search - cellphone. Alibaba.com http://www.alibaba.com/trade/search?SearchT ext $=$ cellphone\&advancesearch $2=$ Search\&opt $=$ AND\&Index Area=company_en\&business Type $=\mathrm{I}$ [Consultado el 20 de Julio de 20II].

BELK, J. K. Three topics that continue to be misunderstood by the wireless world. Qualcomm Incorporated. [S.I.], p. I5. 2003.

BUSINESS NEWS AMERICAS (20I I). Huawei Technologies Co Ltd. Business News Americas http://www.bnamericas. com/company-profile/es/Huawei_Technologies_Co,_Ltd,Huawei [Consultado el I3 de Mayo de 20II].

DOTMOBI (20I I). Global mobile statistics 20I I. Mobithinking http://mobithinking.com/mobile-marketing-tools/latestmobile-stats [Consultado el 20 de Mayo de $20 \mathrm{II}$ ].

EDWARDS, B. (2009). Evolution of the Cell Phone. PCWorld http://www.pcworld.com/article/I 73033/evolution_of_the_ cell_phone.html [Consultado el 20 de Mayo de 20I I].

FARLEY,T. Telektronikk, v. 3, n. 4, p. 22-34, (2005).

FARLEY, T. (2006). http://www.privateline.com/mt_cellbasics/ix_code_division_multiple_access_is $95 /$ a_before_we begin_a_cellular_radio_review/ [Consultado el 12 de Abril de $20 \mathrm{II}$.

HUAWEI TECHNOLOGIES CO., LTD. (20II). Corporate Information. About Huawei http://www.huawei.com/en/ about-huawei/corporate-info/index.htm [Consultado el 20 de Marzo de $201 \mathrm{I}$ ].
IDC (2007). Record-Setting Fourth Quarter Shipments Propel Worldwide Mobile Phones Past One Billion Unit Mark, Says IDC. Business Wire http://www.businesswire.com/ news/home/20070 I 25005456/en/Record-Setting-FourthQuarter-Shipments-Propel-Worldwide-Mobile [Consultado el 10 de Mayo de 20II].

IDC (2008). Financial Crisis Hits Mobile Phone Market as Third Quarter Shipment Growth Drops To 3.2\%,According to IDC. IDC-Cema http://www.idc-cema.com/newsletters/ October08/PR3.html [Consultado el 25 de Mayo de 20I I].

IDC (2010). Apple Joins Top Five Mobile Phone Vendors as Worldwide Market Grows Nearly I5\% in Third Quarter,According to IDC. IDC http://www.idc.com/about/viewpressrelease.jsp?containerld=prUS225500I0

IDC (20I I). Android Rises, Symbian^3 and Windows Phone 7 Launch as Worldwide Smartphone Shipments Increase 87.2\% Year Over Year, According to IDC. IDC http://www. idc.com/about/viewpressrelease.jsp?containerld=prUS2268 9 I I \& \&sectionld=null\&elementld=null\&pageType=SYNOPS IS [Consultado el 20 de Abril de $20 \mathrm{II}$ ].

KEITH, R. D. (2004a). http://iml.jou.ufl.edu/projects/fall04/ keith/historyl.htm [Consultado el 20 de Marzo de 20I I].

KEITH, R. D. (2004b). http://iml.jou.ufl.edu/projects/fall04/ keith/Works.htm [Consultado el 20 de Marzo de 20l I].

KÜRTÖSSY, J. Innovation indicators derived from patent data. Periodica Polytechnica Ser. Man. Sci., v. I2, n. I, p. 9 I100, (2004).

MIER, D. (2010). http://dianamier 1990.blogspot. com/2010/09/red-de-celdas.html [Consultado el 10 de Diciembre de 20II].

MOBILEWORLD (2008). GSM Technologies - TDMA - GSM - UMTS - CDMA. TECHGSM http://www.techgsm.com/ page/gsm-technologies/gsm-technologies-network-tdmacdma-umts.html [Consultado el 24 de Marzo de 20I I].

OECD. (2009). Manual de estadísticas de patentes de la OCDE. [S.I.]: [s.n.].

OEPM (20I I). Oficina Española de Patentes y Marcas. OEPM http://cip.oepm.es/ipcpub [Consultado el 20 de Junio de $2011]$.

OMPI (20II). Patentscope. OMPI http://www.wipo.int/patentscope/es/ [Consultado el 20 de Abril de 20I I].

ISSN: 07 I8-2724. (http://www.jotmi.org)

Journal of Technology Management \& Innovation (c) Universidad Alberto Hurtado, Facultad de Economía y Negocios. 
PEARSON EDUCATION, INC. (2009). Cell Phone Subscribers in the U.S., 1985-2008. Infoplease http://www.infoplease. com/ipa/A0933563.html [Consultado el 4 de Junio de 20I I].

PENALVA, J. (2007). http://www.xataka.com/moviles/iphonetelefono-movil-de-apple-completo [Consultado el 20 de Diciembre de 20II].

PINTO, M. (20II). http://www.mariapinto.es/alfineees/doc/ patentes.ppt [Consultado el 15 de Diciembre de 20II].

PLUNKETT RESEARCH (20I la). Huawei Technologies Co Ltd. Plunkett Research http://www.plunkettresearchonline. com/ResearchCenter/Profiles/view2.aspx? Industry= 14\&Co mpany=HUAWEI+TECHNOLOGIES+CO+LTD [Consultado el 20 de Mayo de 20I I].

PLUNKETT RESEARCH (20l l b). Nokia Siemens Networks. Plunkett Research http://www.plunkettresearchonline.com/ ResearchCenter/Profiles/view2.aspx? Industry=3\&Compan $y=N O K I A+S I E M E N S+N E T W O R K S$ [Consultado el 20 de Mayo de 20II].

PLUNKETT RESEARCH (20Ilc). ZTE CORPORATION. Plunkett Research http://www.plunkettresearchonline.com/ ResearchCenter/Profiles/view2.aspx? Industry=3\&Compa $n y=Z T E+C O R P O R A T I O N$ [Consultado el 30 de Mayo de 20II].

RUA (20II). Repositorio Institucional de la Universidad de Alicante. ANÁLISIS DE CORRESPONDENCIAS http:// rua.ua.es/dspace/bitstream//0045//96/5/I/ANALISIS_DE_ CORRESPONDENCIAS.doc [Consultado el 10 de Agosto de $20 \mathrm{II}$.

SALVADOR, M. (2003). Análisis de Correspondencias http:// www.5campus.com/leccion/correspondencias [Consultado el 10 de Agosto de 20I I].

STOUFFER, D. (2008). Voice Over Internet Protocol: Extraordinary. Voip For Mobile http://voip4mobileworld.com/ voice-over-internet-protocol-extraordinary/ [Consultado el 25 de Mayo de $20 \mathrm{II}$ ].

THANH, D.V.The mobile phone: Its evolution from a communication. Telektronikk, v. 3, n. 4, (2005).

UIT (20II). Free statistics. ICT Data and Statistics (IDS) http://www.itu.int/lTU-D/ict/statistics/ [Consultado el 25 de Junio de 20II].
WEBDESIGNER DEPOT (2009). The Evolution of Cell Phone Design Between 1983-2009. Webdesigner Depot http://www.webdesignerdepot.com/2009/05/the-evolutionof-cell-phone-design-between-1983-2009/ [Consultado el 20 de Mayo de 20II].

YAHOO FINANCE (20lla). Nokia Corporation (NOK). Yahoo Finance http://finance.yahoo.com/q?s=NOK [Consultado el 12 de Abril de 20I I].

YAHOO FINANCE (20I lb). ZTE Corp. (ZTCOY.PK). Yahoo Finance http://finance.yahoo.com/q?s=ZTCOY.PK\&ql=I [Consultado el 12 de Abril de 20II].

ZTE CORPORATION (20II). Company Overview. About ZTE http://wwwen.zte.com.cn/en/about/corporate_information/ [Consultado el 10 de Junio de $20 \mathrm{II}$ ]. 